Trivent Publishing

(C) The Authors, 2016

Available online at http://trivent-publishing.eu/

Series: Engineering and Industry

Volume: Watershed and River Basin Management

\title{
Sustainable River Basin Management under the European Water Framework Directive: an Effective Protection of Drinking-Water Resources
}

\author{
S. Wuijts, ${ }^{1}$ H.F.M.W. van Rijswick ${ }^{2}$ \\ ${ }^{1}$ Centre for Sustainability, Environment and Health (DMG), National Institute for Public Health and the \\ Environment (RIVM), P.O. Box 1, 3720 BA Bilthoven, The Netherlands, susanne.wuijts@ rivm.nl \\ ${ }^{2}$ Utrecht Centre for Water, Oceans and Sustainability Law, Utrecht University, Achter Sint Pieter 200, 3512 HT \\ Utrecht, The Netherlands, H.vanRijswick@law.uu.nl
}

\begin{abstract}
In the Netherlands drinking water is produced both from surface water and groundwater. Due to the shortage of space, resources are often found in combination with other activities, such as those pertaining to industry or agriculture, in the same neighbourhood. These combinations impose strong demands on the water management of the river basin and the legal instruments that are at hand. The European Water Framework Directive (WFD, 2000) ensures sustainable availability of good-quality groundwater and surface water. Current drinking-water directives are partially addressed in the WFD, along with 'new' obligations such as the river basin approach. One of these obligations is to develop suitable measures for meeting the drinking-water standards taken up in the regulations and to reduce the time needed for treatment of drinking water. This study focused on setting up a protocol elaborated and evaluated at three different abstraction sites (pilots) - to develop these measures. The so-called 'area dossier' offers good insight into the factors influencing water quality for all parties involved and makes it possible to develop suitable and effective measures. The general approach taken in this protocol will enable it to be used by other European Member States.
\end{abstract}

\section{Keywords}

Dossier for the area; drinking water; spatial plans; suitable measures; Water Framework Directive

This is an Open Access article distributed in accordance with the Creative Commons Attribution Non Commercial (CC-BYNC-ND 4.0) license, which permits others to copy or share the article, provided original work is properly cited and that this is not done for commercial purposes. Users may not remix, transform, or build upon the material and may not distribute the modified material (http://creativecommons.org/licenses/by-nc/4.0/) 


\section{Introduction}

Access to safe drinking water is an important health issue worldwide. The sustainable provision of safe drinking water requires the development of a multifaceted water resource management plan and a close cooperation between national, regional and local authorities that is embedded in legislation. Several health-orientated conferences have taken place on this subject during recent decades. The United Nations (UN) General Assembly recently declared the period from 2005 to 2015 as "the International Decade for Action, "Water for Life"'. In 2002, the Regional Office for Europe of the World Health Organization developed The Protocol on Water and Health. The aim of this Protocol, the provisions of which cover most water environments, is to promote the protection of human health through improvements to water management. One of its more important provisions is that parties agree to set targets, thereby ensuring that tools are available to assess whether actual progress is being made.

The European Water Framework Directive (WFD, 2000) was implemented to establish a European framework that would ensure the sustainable availability of good quality groundwater and surface water. Current European drinking water related directives are partially addressed in the WFD, along with 'new' obligations, such as the river basin approach. One of these obligations encompasses the development of suitable measures in order to meet the drinking water regulations and reach the targetreduction in the drinking water treatment within the agreed-upon time parameters.

\section{Drinking water production in the Netherlands}

In the Netherlands drinking water is drawn from both surface water and groundwater resources. In terms of water management, the Netherlands forms part of four river basins that are not constrained by national borders (Figure 1). As a result, water quality is strongly determined by the actions of neighbouring countries as well as by those of the Netherlands. These river basins can be characterized as a being highly industrialized and densely inhabited basins as well as multifunctional.

Due to the shortage of space in the Netherlands, drinking water resources are often found in close proximity with areas affected by various anthropogenic activities, such as those pertaining to industry or agriculture. These combinations impose strong demands on the water management programme of the river basins and the legal instruments that are at hand. Good spatial planning and land use management policies can provide a balance between conflicting activities, thereby safeguarding drinking water objectives if inadequate attention has been paid to the protection of drinking water resources. 


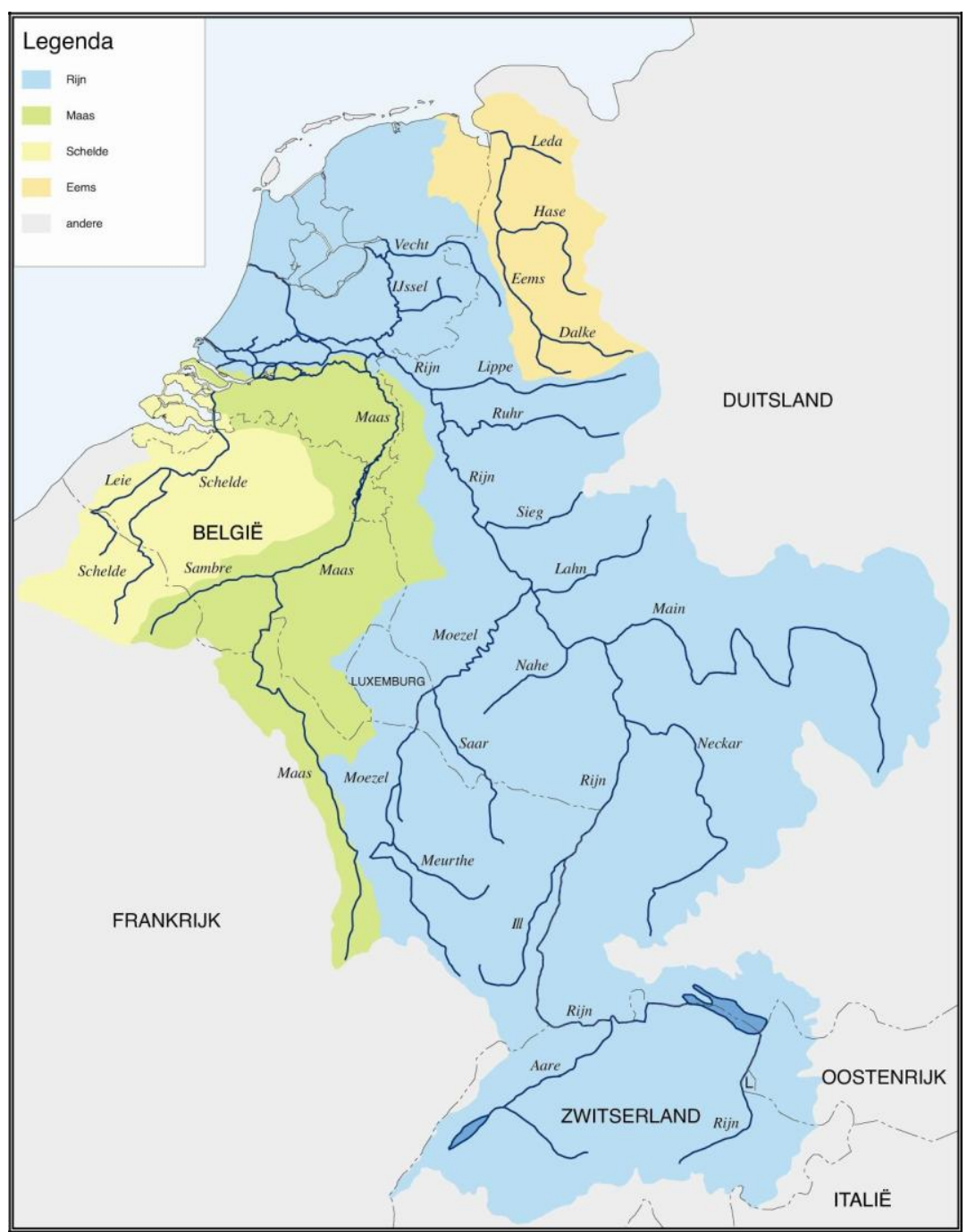

Fig. 1. The Netherlands form part of four international River Basins: the Rhine, the Meuse, the Scheldt and the Ems

Table 1. Protection policy drinking water resources, surface water and groundwater

\begin{tabular}{lll}
\hline & Surface Water & Groundwater \\
\hline Current & $\square$ Function Drinking Water & $\square$ Preventive protection policy in \\
& assessed in terms of & zones (60 days, 25 years and \\
& waterbodies & catchment area) with (spatial) \\
& Quality standards for this & limitations on land use. \\
& function are applicable in this & \\
& waterbody \\
\hline 'New' & $\square$ Register of protected areas \\
$($ WFD/GWD") & $\square$ Effective measures directly related to water quality \\
$\cdot$ & Quality standards for groundwater \\
$\cdot$ & Safeguard zones (optional) \\
GWD, European Union Groundwater Directive, 2003
\end{tabular}




\section{Dossiers for the area}

Based on the results of a previous study conducted by the RIVM (Wuijts and Van Rijswick, 2007a) a so-called dossier for the area has been established as an instrument that offers support in developing protection measures around an abstraction site. Data on water quality, water quantity (as far as it is relevant to water quality) and protection policy are collected and analysed in conjunction as a whole dataset. Based on the analysis, measures are being proposed that are directly related to resolving the water quality issues at the abstraction site. The actual realization of the measures, however, is a political issue, and choices will have to be made by the responsible authority or by the water company itself.

The Ministry of Housing, Spatial Planning and the Environment requested the RIVM to develop a protocol for the so-called dossier for the area and to test this protocol in practice. The questions to be addressed in this test were:

- Which information (data) should be collected in the dossier?

- Which authority is to be in charge of creating and updating the dossier and selecting and carrying out measures?

- What status should be given to the dossier?

- Where should the dossier be legally anchored (national, provincial, municipal authorities, or all of these)?

- How should the dossier for the area relate to the implementation process of the Water Framework Directive?

In this study, a protocol has been formulated to develop suitable measures (Wuijts et al., 2007b). This protocol is elaborated and evaluated at three different abstraction sites (groundwater, surface water and river bank filtration). Figure 2 presents a summary of one of the dossiers as an example. At the abstraction site described in this figure, drinking water is produced by river-bank filtration and, therefore, both groundwater and surface water aspects are included in the dossier.

The 'dossiers for the area' contains information on:

- Characteristics of the abstraction and treatment process and its capability of removing certain types of substances;

- Hydro(geo)logical characteristics of the resource and its characteristics for distributing polluting substances;

- Activities taking place in the area of influence, including potential pollution, with both point sources as diffuse sources;

- Analysis of the water quality: current and expected quality issues based on monitoring results;

- Legal framework, policy in practice and gaps, such as authorizations for pesticides, permits in the broad field of environmental and water law, general rules replacing permits, protection areas, agriculture regulation, among others;

- Measures, including time scales and responsibilities.

Anchoring of the measures takes place within the constraints of existing legal documents, such as environmental and spatial plans/programmes, and the instruments are included in the WFD programmes of measures.

The relationship between the 'dossier for the area' and other relevant plans is presented in Figure 3. 


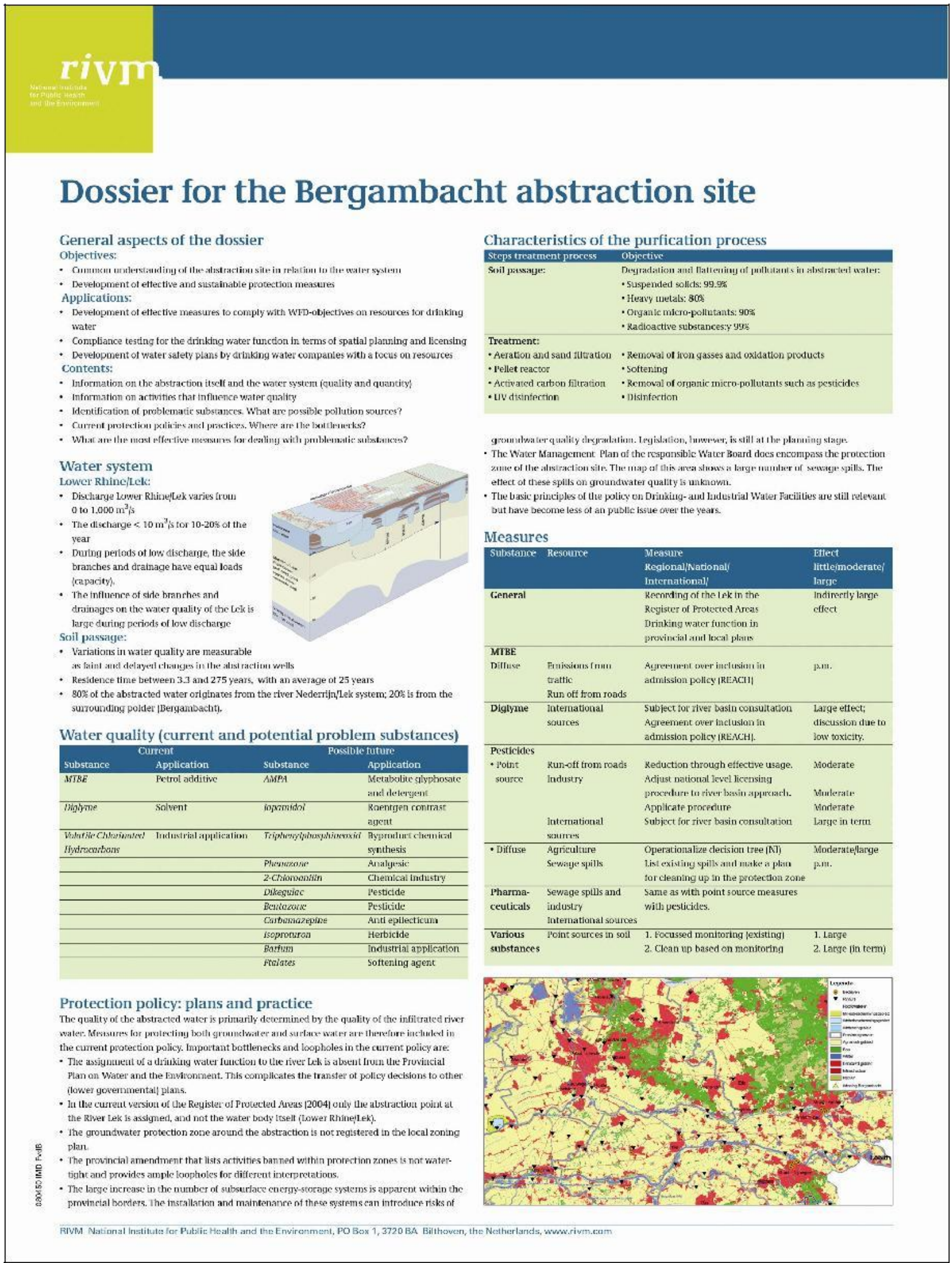

Fig. 2. Summary dossier for Bergambacht abstraction site 


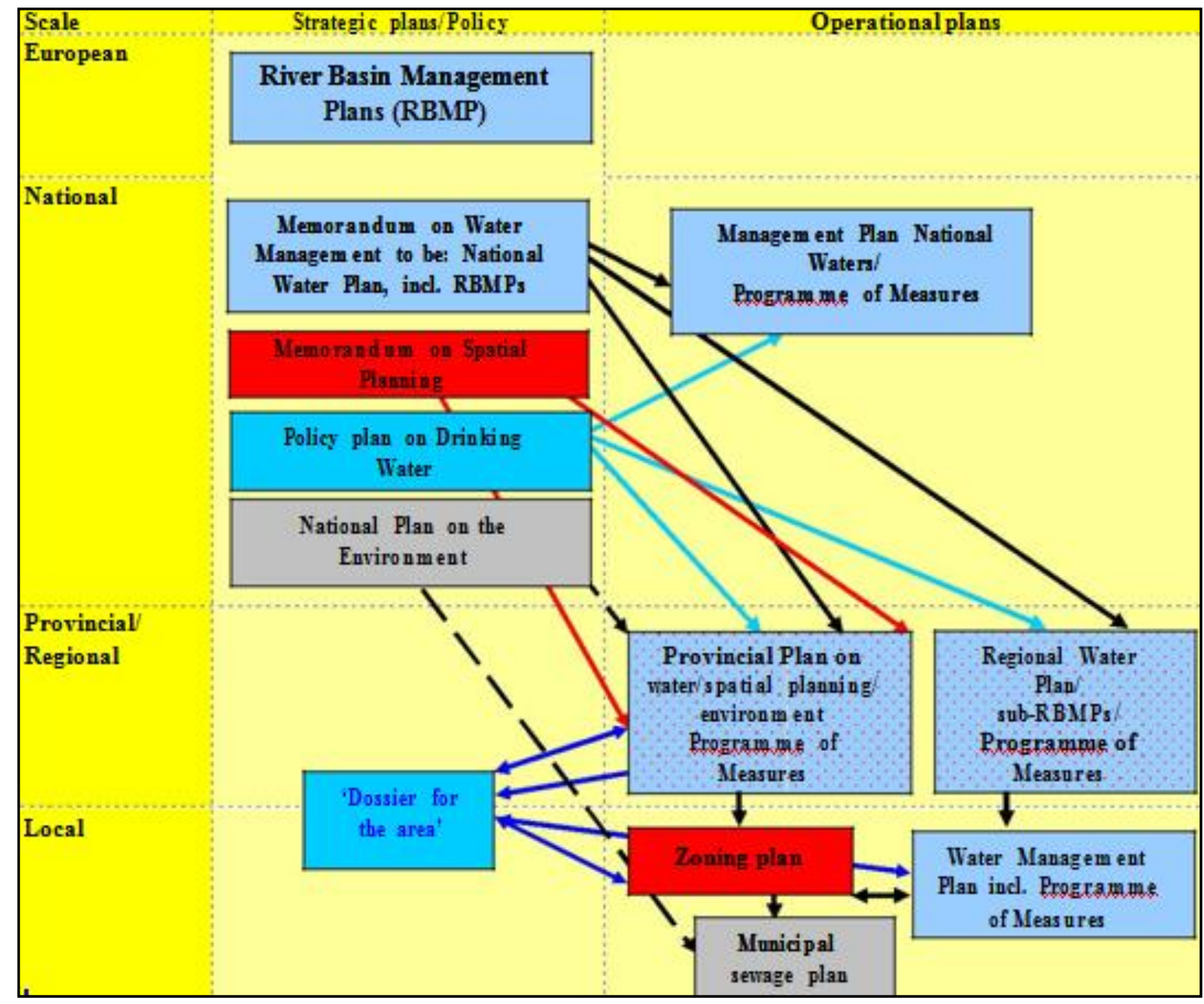

Fig. 3. Relationship between 'dossiers for the area', River Basin Management Plans and other existing and new relevant plans in the Netherlands

The results of the pilot trials have been discussed in a workshop attended by representatives of all relevant stakeholders, including drinking water companies, ministries, provinces, water authorities and research institutes. The results show that the so-called 'dossier for the area' is a reliable instrument for collecting all data that is pertinent to the protection of the resource. This information provides the foundation for developing protection measures that will be based on prevention and risk management. The dossier for the area has, in this respect, added value and can be further improved by clarifying the contribution of individual pollutants and spills on water quality.

\section{Conclusions}

- The so-called 'dossier for the area' provides all relevant stakeholders with a good insight into the factors influencing water quality and facilitates the development of suitable and effective measures. The general approach adopted in this protocol ensures that the dossier is utilizable by other European Member States.

- A legal anchoring of the dossiers is advisable, since this provides a higher level of assurance that all necessary information and the contents of the dossier are accessible. Both the Dutch 
Environmental Act and the renewed Dutch Drinking Water Act provide possibilities for anchoring. The most logical place for this anchoring is within the Drinking Water Act, since this Act obliges drinking water companies to formulate plans for water supply that encompass the delivery of that water from resource to tap.

- Management of the formulation and maintenance processes pertaining to the 'dossier for the area' are necessary since measures cover multiple policy areas such as water, spatial planning and the environment and involve authorities ranging from provinces to water boards and municipalities. The provinces would appear to be the best level of government to be in charge of the dossiers in terms of the management process due to the fact that in the Netherlands the provinces have been given the legal authority to manage the integration of policy in the broad field of environmental law, including nature conservation, water management and spatial planning. Most other governmental bodies either only handle one or a few aspects of the protection of drink water resources, or they do not have adequate regulatory powers to influence decision-making at the regional level. This situation may be different in other countries.

- The date when the River Basin Management Plan is to be implemented within the time framework of the WFD is approaching rapidly. As time is of an essence, attention must be given - at the administrative level - to how the 'dossiers for the area' will fit into this Plan. Measures are currently being outlined for the sub-basins, although the status of this outline varies from subbasin to sub-basin. It may be possible to fit the 'dossiers for the area' into the up-coming further elaboration of the measures and the harmonization of measures between sub-basins. This step, however, places pressure on the administrative decision-making process and the formulation of the dossiers themselves. Another, more realistic, option is to fit the dossiers into the development of the next series of River Basin Management Plans (2015). This would enable practical testing of the 'dossiers of the area' during the time period of the first River Basin Management Plan and, consequently, further development and fine-tuning of this instrument.

\section{Future steps}

Four steps can be identified as a continuation of this project. Depending on the administrative decision-making process, these can be carried out sequentially:

- The preparation of a basic decision on the introduction of the 'dossier for the area' by all of the stakeholders; initiated by the Ministry of Housing, Spatial Planning and the Environment;

- The actual decision-making by all responsible authorities on the introduction of the 'dossier for the area';

- Adjustment and refinement of the protocol;

- Implementation of the 'dossier for the area' for all abstraction sites.

\section{References}

Wuijts, S., Rijswick, H.F.M.W. van (2007a) (in Dutch, English summary). Drinking-water aspects and the Water Framework Directive: protection of drinking-water from surface water. RIVM report 734301028, Bilthoven, The Netherlands.

Wuijts, S., Rijswick, H.F.M.W. van, Dik, H.H.J. (2007b) (in Dutch, English summary).

'Dossiers for the area' for drinking water resources. RIVM report 734301032, Bilthoven, The Netherlands. 